\title{
PHOTO ESSAY
}

\section{A DISASTROUS YEAR FOR BALD EAGLES AT LAC LARONGE SASKATCHEWAN IN 2013}

\section{DALE MIERAU c/o SMRC 479 FirstAvenue North Saskatoon, SK S7K 1X5}

I have owned a cabin on a small island on Lac LaRonge since 1984. The cabin was built in 1975 but was not used until 1984. It sits on a 600 meter by 100 -meter rocky island that is 15 kilometers from the town of La Ronge.

Recognizing a Change in Breeding Success of the Bald Eagle

Bald Eagles live long lives and don't breed until the age of six years. Casual observation of population density might not detect a decline of successful breeding pairs. A failure to notice a reduced number of fledgling Bald Eagles could limit the possibilities for a reversal.

Years ago I developed an interest in Bald Eagles and recorded my observations with still images. 2013 was a disastrous year for Bald Eagles on Lac LaRonge, Saskatchewan. Only two nests of nine produced young and only one young bird survived past the fourth week.

Normal Bald Eagle Distribution in Recent Years.

I observed 11 Bald Eagle nests in 2012. The location of the cabin and the nearby nests can be seen in Figure 1.

Nine of the nests were active in 2012 with a pair of eagles attending the nest. The square markers identify the active nests situated within the map area. Three additional active nests were outside the map area. Two nests, identified by the round markers, were abandoned.

Most well established Bald Eagle nests on Lac La Ronge are in birch trees. Newly built nests, or nests that were recently moved, tend to be in tall spruce trees in close proximity to the eventual site of an established nest.

A well-established nest in a birch at the McKee Island site (most easterly round marker) fell down in 2009. The pair moved the nest to a tall spruce on McCulloch Island identified by a star. They moved the nest to a birch closer to the water in 2012.

A pair of birds abandoned a wellestablished nest on a tall dead tree on an exposed island (the most westerly island with the round marker) in 2012. They built a new nest in a tall spruce on a small island at Camp Island (square marker).

Four nests produced young and I know that three of the young birds fledged in 2012. The four productive nests were at the McCulloch Island Site (identified with a star), Camp Island Site, the Big Island Site (both identified by squares) and the LaRonge Site that is just east of the town site and not in the map area. 


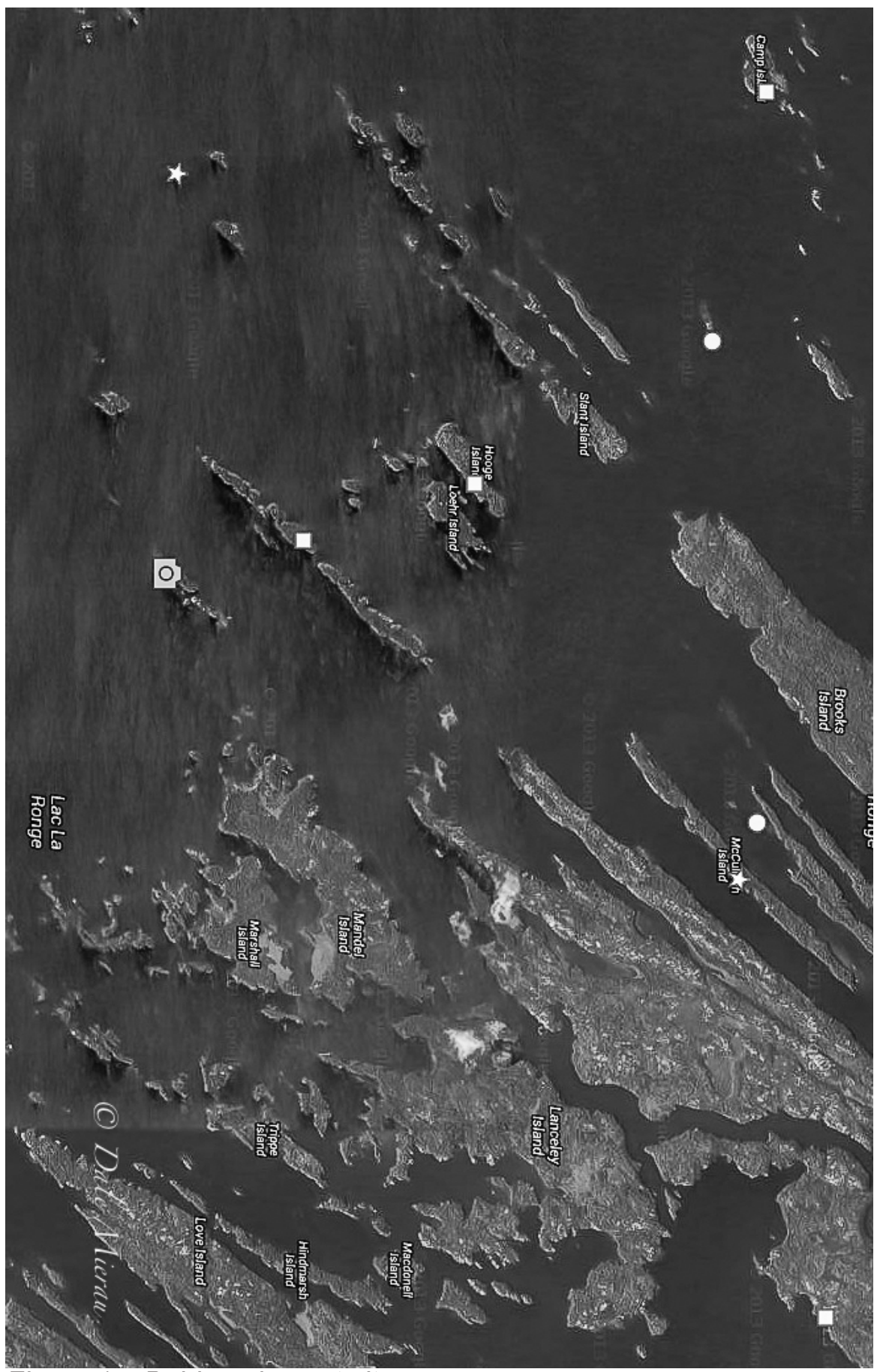

Figure 1 - Bald eagle nest sites 


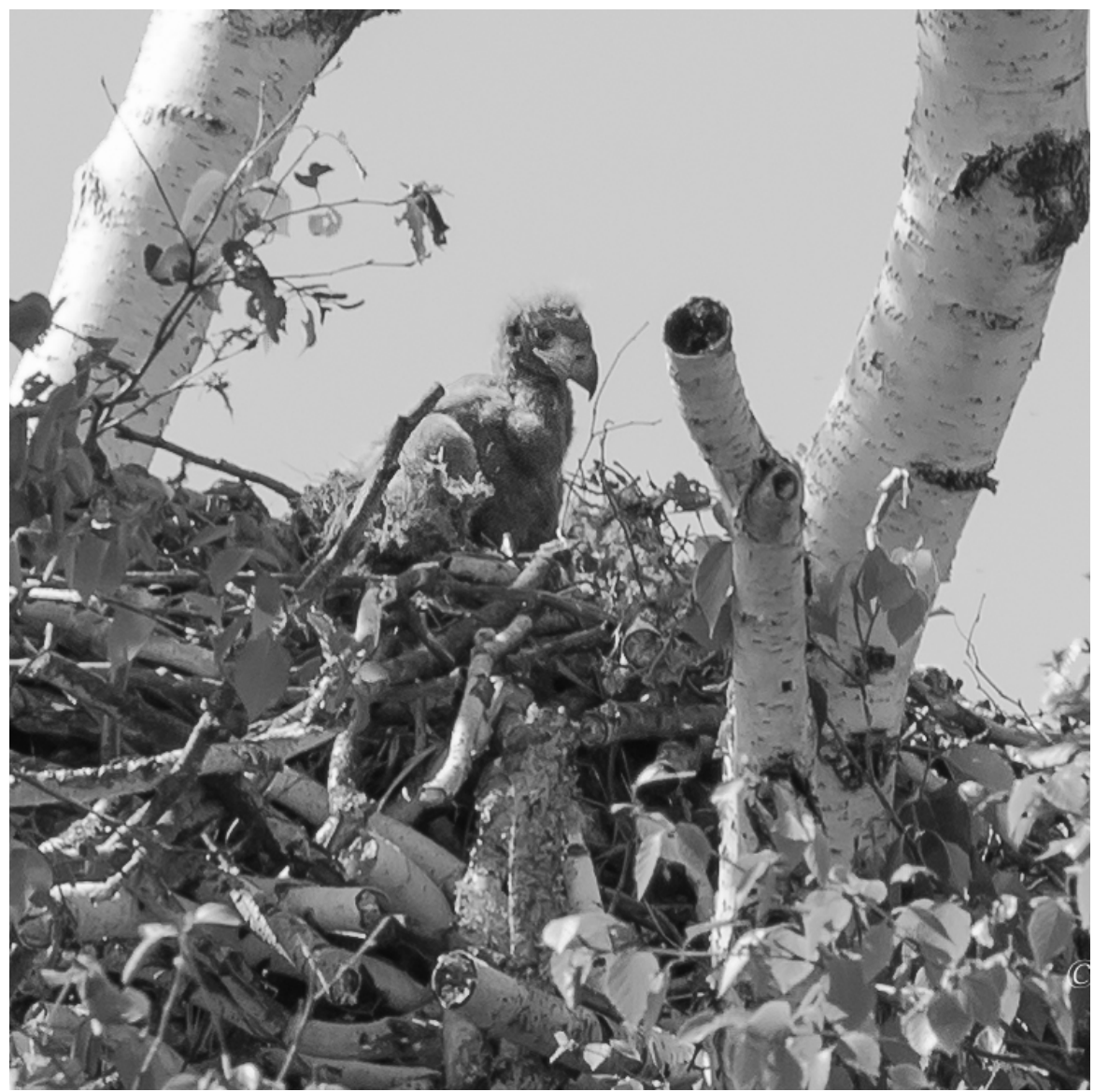

Figure 2 - Nestling, 16 June 2013 at McCulloch Island nest

I did not see the fledgling at the La Ronge site, but I might have not noticed it because I visited it rarely. Using distinctive developmental features of the head and distinct feather patterns I believe two of the birds that fledged in 2012 returned to the area 2013.

In 2013, a disastrous year, the only productive nest that produced a fledgling was at the Lisee site (most southerly star marker). This nest sits on an exposed small island that is 2.5 kilometers southwest of our cabin.
The Lisee nest was not productive in 2012. In the spring of 2013 , the pair at the Lisee site moved the nest from a tall spruce to a more sheltered birch situated in the middle of the island.

Only two of nine active nests hatched young in 2013 (identified by stars on the map) and only one young at the Lisee Site survived beyond four weeks. A nestling was photographed at McCulloch Island nest on 16 June 2013 but it died sometime during the third week in June (Fig. 2). 


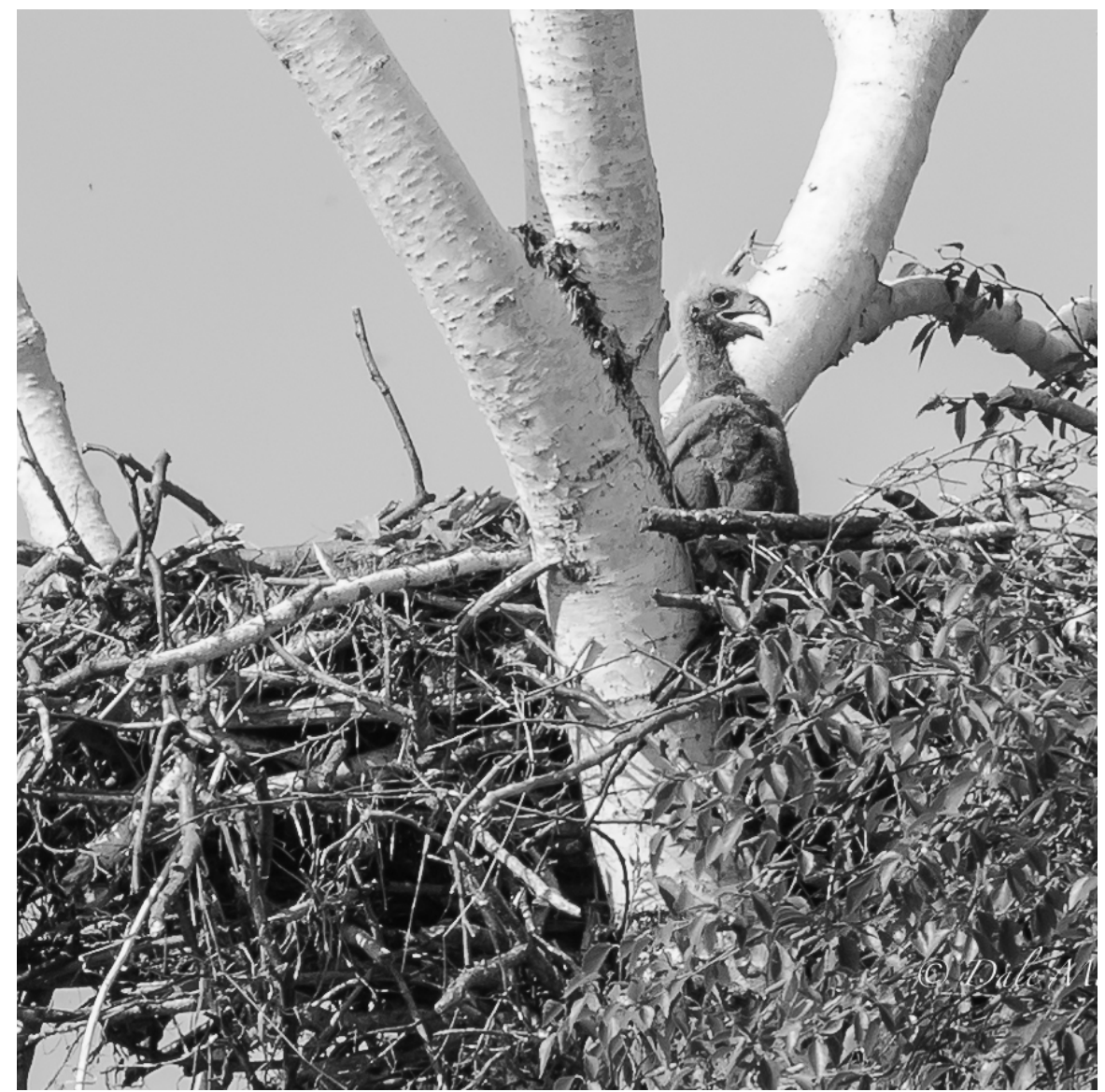

Figure 3 - Nestling, 18 June 2013 at Lisee nest.

Amber, the female young Bald Eagle that I observed in 2013, was sitting in the nest at the Lisee site on 18 June 2013 (Fig. 3).

There was a second hatchling at the Lisee site but I did not see it until its carcass was visible on the edge of the nest on July 2 (Fig. 4)

Amber thrived (Fig 5). Mother did most of the flight training before Amber branched.
Amber was a voracious eater. Father fed her most of the time, even after she fledged (Fig 6).

She was obviously larger than her father and at least as large as her mother in late August (Fig. 7). The male did most of the training to hunt. This family of Bald Eagles did not hunt from the nesting island. Rather they used perches on islands nearby.

What might have contributed to the low breeding success of Bald Eagles on Lac LaRonge in 2013? 


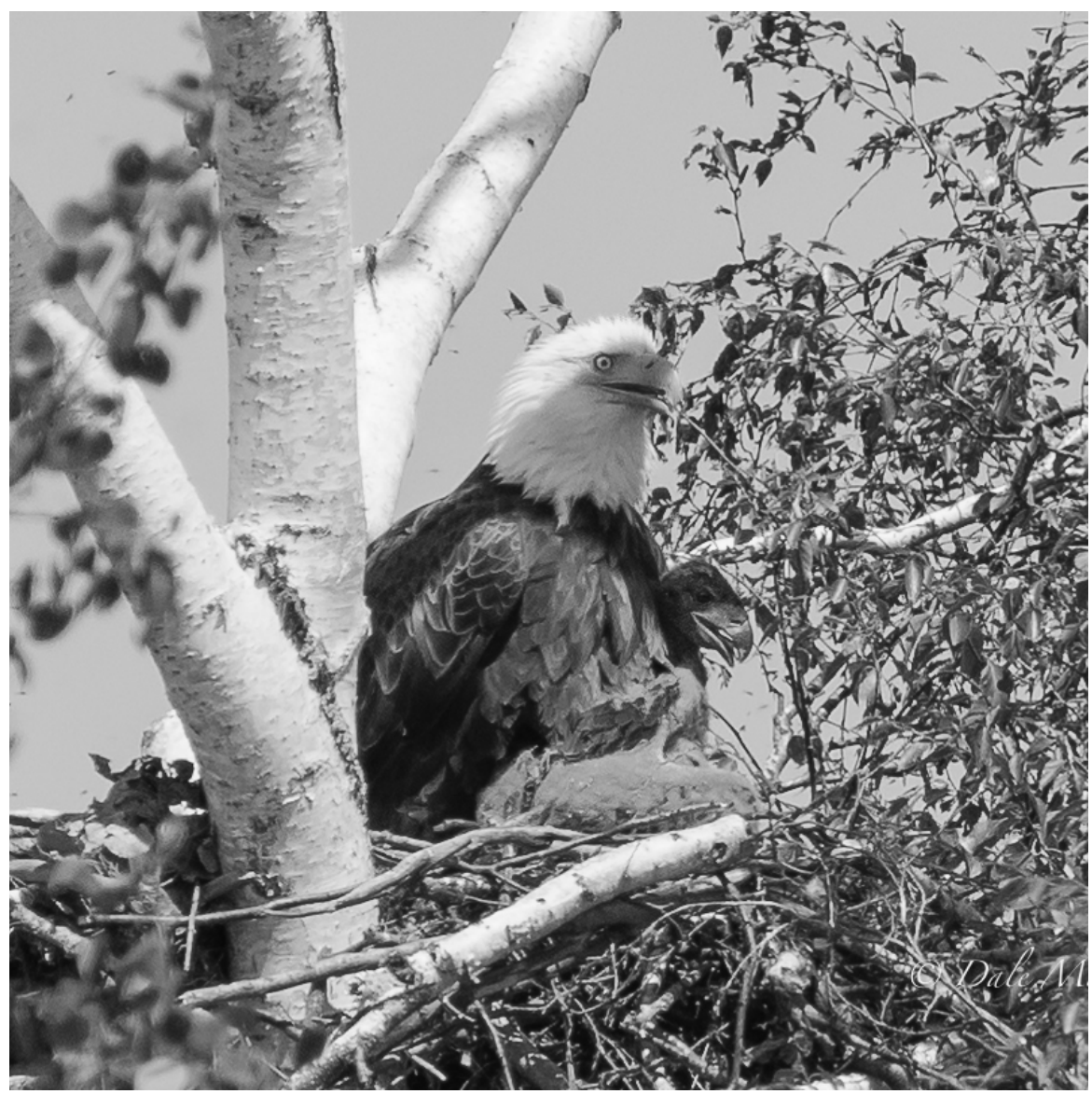

Figure 4 - Adult with nestling, note dead chick on side of nest. 2 July 2013, Lisee nest

1. It could just be an extreme variation of normal.

2. The low rate of breeding success could signal a trend toward a lower number of Bald Eagles on the lake, which could be related to the availability of food. In 2008 an informal assessment of the population of sport fish in Lac La Ronge documented sparse numbers of surface fish such as Northern Pike (Esox lucius). ${ }^{1}$

3. Bald Eagle breeding success is likely adversely affected by bad weather. Females that are in poor physical condition when they arrive at the breeding ground are less likely to breed successfully. In 1975 , a spring blizzard was thought to result in a fifty percent reduction of the expected number fledglings on Besnard Lake and a lower number of fledglings in the Greater Yellowstone Ecosystem. ${ }^{2}$ Spring weather arrived later than usual in Saskatchewan in 2013. There were severe snowstorms in late March and in late April. This 


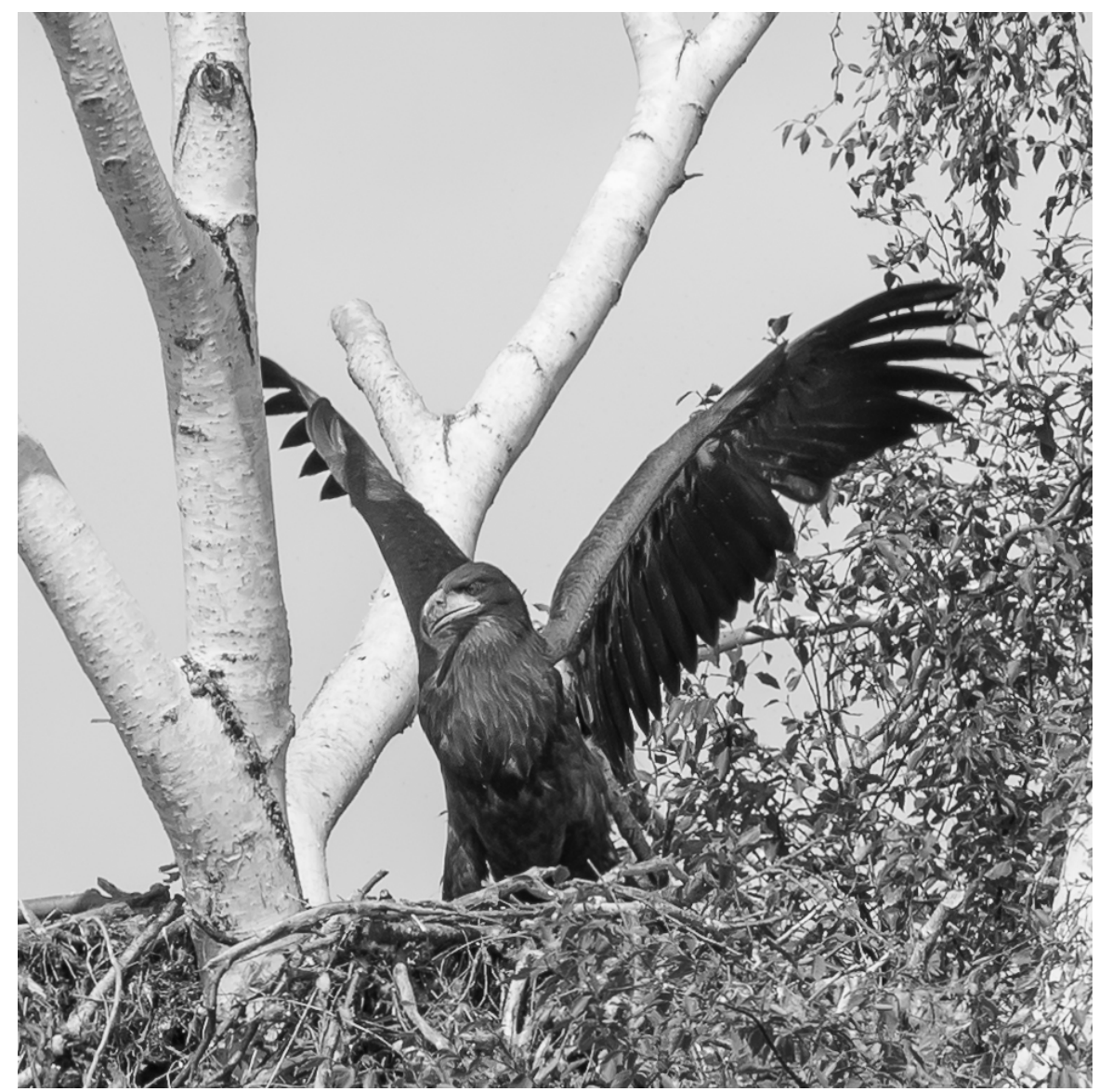

Figure 5 - Nestling strengthening wings, Lisee nest

unusually harsh weather is one of the more likely explanations for the low number of active nests on Lac LaRonge in 2013.

4. A late spring and cool weather might delay the warming of lake water and adversely affect the timely rise of shallow water fish to the shallows where they are available to eagles. In 1996, the ice did not disappear on Lac La Ronge until the first weekend in June, a full two weeks later than usual. The lake ice on Besnard Lake, which is close to Lac LaRonge, did not go off until June 6 . This late spring thaw was followed by a reduced number of occupied nests. ${ }^{3}$

5. The water level at Lac LaRonge reached a record high during the summer of 2011 . The water level remained high through the winter. Water levels remained high in 2012 and were higher than normal in the spring of 2013. The high water level had an adverse effect on plant life near the water's edge (Fig. 8). 


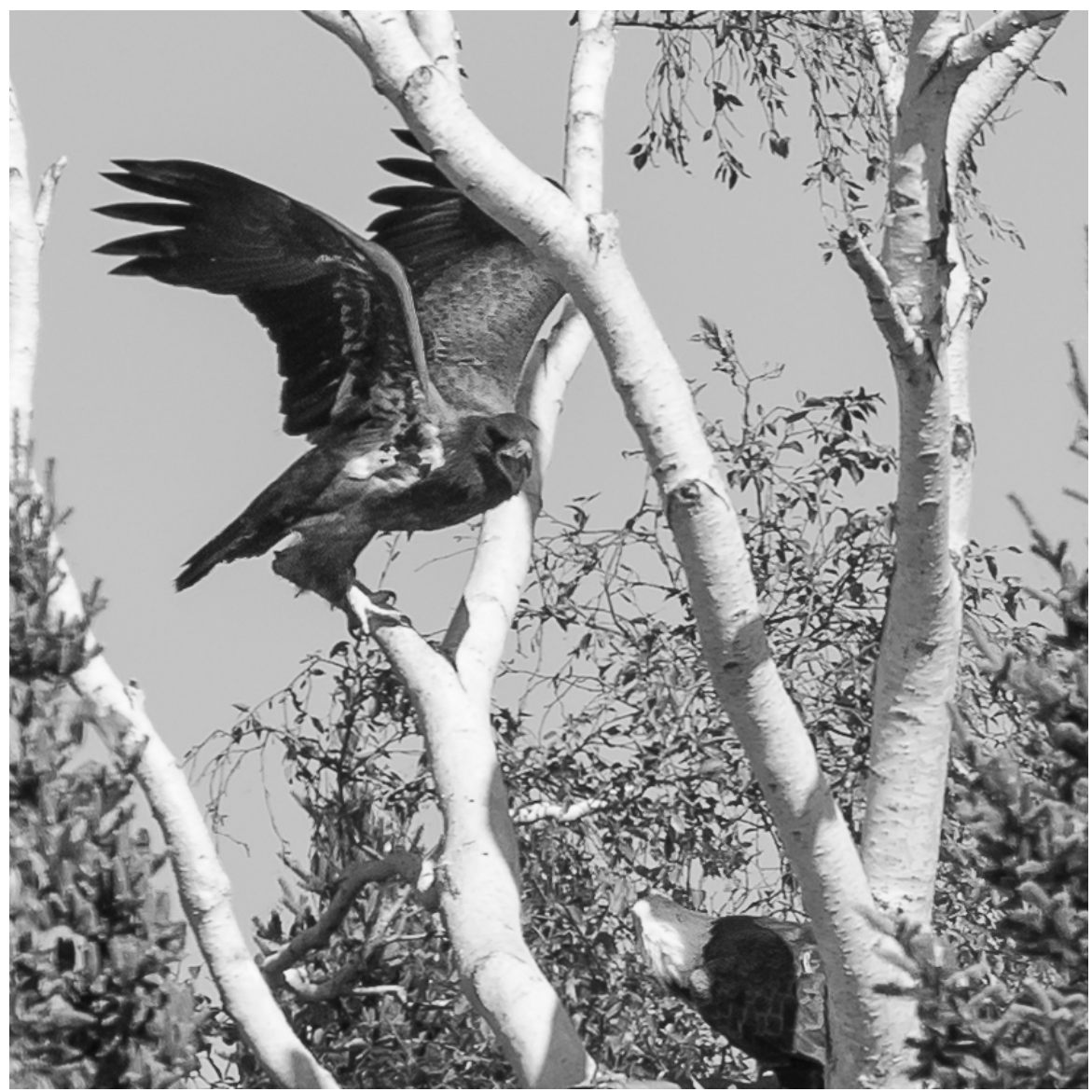

Figure 6 - Lisee nest, fledgling being fed by adult.

While this could have had an effect on shallow water fish populations, these fish are more sensitive to a decline in water levels than an increase. There is no evidence that the populations of burbot (Lota Lota), sucker (Catostomus commersonii) or cisco (Coregonus artedi) are on the decline at Lac La Ronge. ${ }^{4}$ It is possible, though, that the high water levels had an adverse effect, not on the number of fish, but on the availability of shallow water fish to feeding Bald Eagles.
On 13 August 2013, Amber's afternoon meal was a 2-pound burbot. The male, holding the fish, did most of the hunting and feeding at this stage (Fig. 9).

6. A high ratio of first, second, third and fourth year Bald Eagles might increase the competition for food. In the summer of 2013, I saw two one-year-old birds, two two-year-olds, one three-year-old and one four-year-old birds in the 


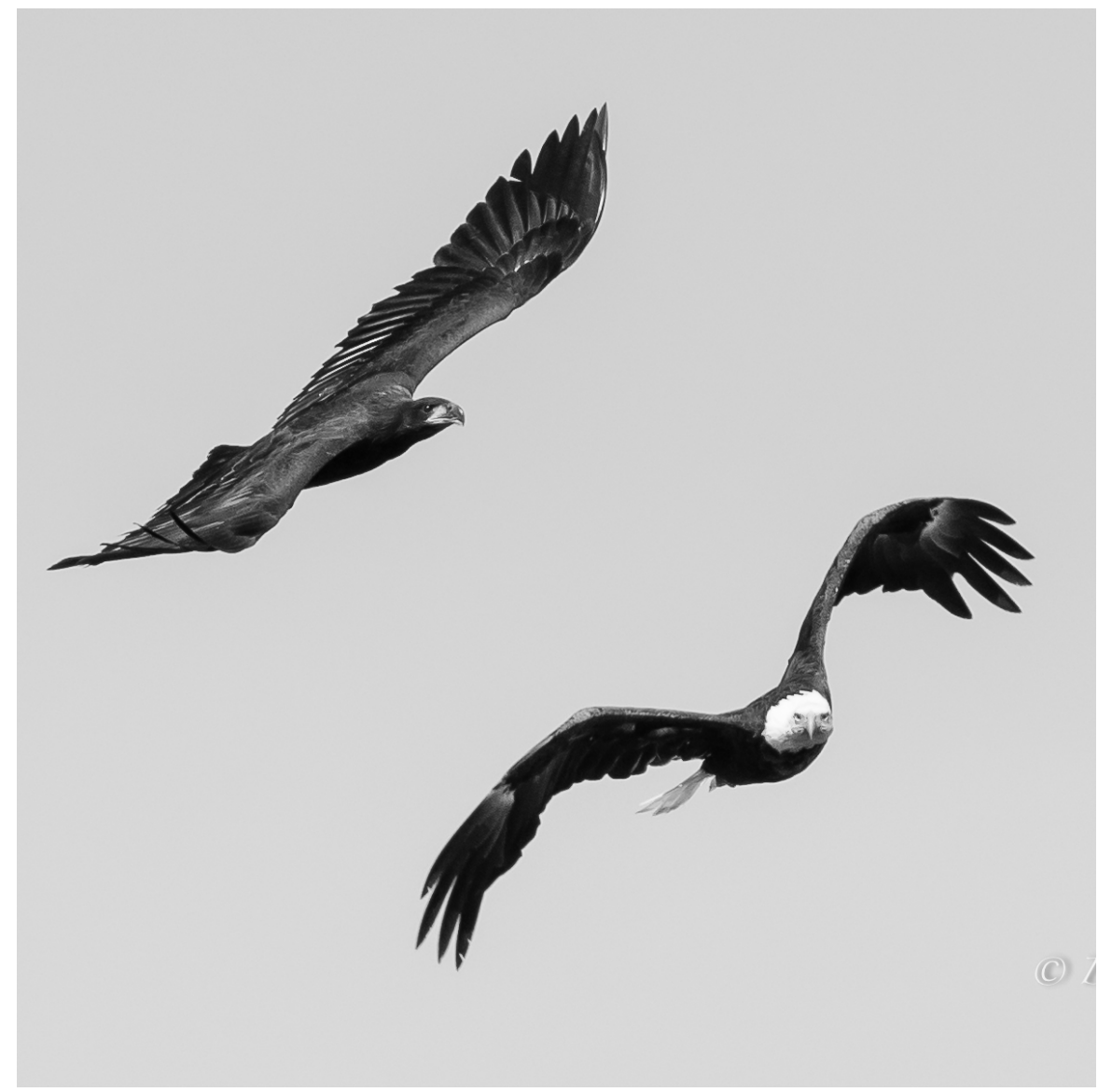

Figure 7 - Adult and juvenile, late August 2013, Lisee site

area under observation. These see it until mid July. It remained subadult birds remained fairly near the nest through the rest of close to the eight nests that did not the summer and fall often sitting produce a fledgling, including the near the nest with one or both nest at the McCulloch site. Adult mature adults. Its characteristic Bald Eagles protect an active nest with some vigor. However, eagles with empty nests do not seem to be nearly as territorial. The oneyear-old bird that fledged at the McCulloch site in 2012 returned to the nesting area on McCulloch Island in 2013. However, I did not markings as a one-year-old and an unusual appearance of one of its eyes convinced me that it was same bird that I saw as a fledgling the year before (Fig 10).

The two mature Bald Eagles at the McColluch site did not seem 


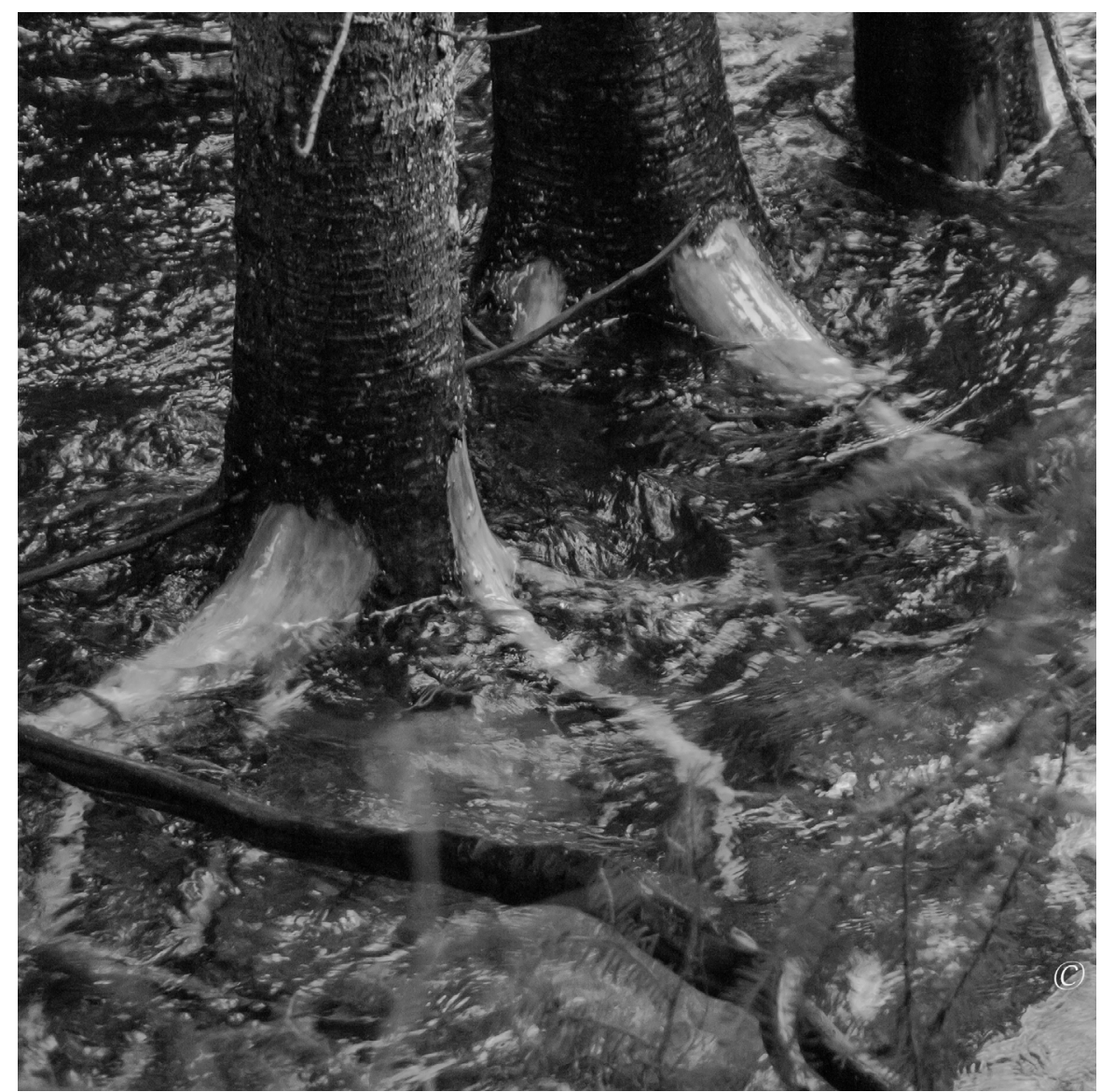

Figure 8 - High water levels around tree roots, Lac LaRonge, spring 2013

at all disturbed by the presence of the one-year-old even though the nest did produce young that did not survive past 16 June. I did not see any sub adult eagles within a kilometer of the Lisee site in the summer of 2013 . This observation is curious because there is evidence that sub adult Bald Eagles in the Chesapeake Bay area rarely return to their lake of origin. ${ }^{4}$ This might not be the case in the Lac La Ronge area.
I didn't get on the lake until the second weekend in June in 2013. I hope spring arrives early in 2014 so I can get on the lake in May. However, the likelihood of this is waning due to the unusually cold winter and the large amount of snow on the ice. A high priority in 2014 will be to observe the number and ages of returning of sub adults. This will depend on light winds to allow more time on the water. 


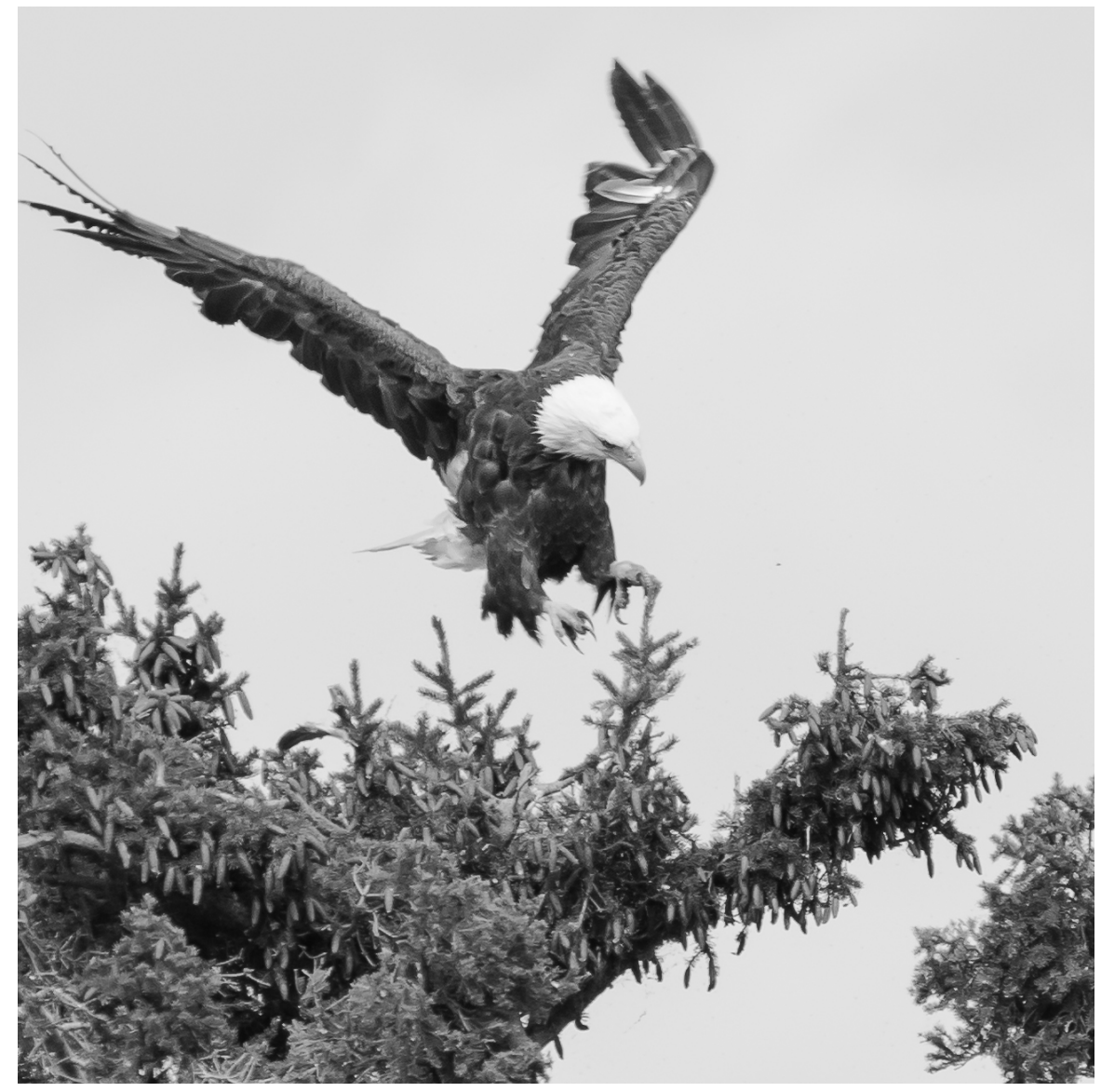

Figure 9 - Adult, Lisee nest.

The author acknowledges the support and encouragement of Stuart Houston. Mark Duffy provided valuable information about fish stocks at Lac LaRonge.

1. http://www.environment.gov. sk.ca/adx/aspx/adxGetMedia. aspx?DoclD $=5 \mathrm{c} 5790 \mathrm{e} 4$ 1 e a d - 4 a $91-9$ d 4 e fab6f4ea71c\&MedialD=edc6cb3f1479-4f81-b422-20540023b85 6\&Filename $=$ Fish+Facts +2008 . 2. Gerrard JM, Berolotti GR (1988) The Bald Eagle: Haunts and Habitats of a Wilderness Monarch. Western Producer Prairie Books.

3. Gerrard JM. Personal communication with CS Houston.

4. Duffy M. Fisheries Biologist for the Ministry of Environment, Lac La Ronge, SK. Personal communication 


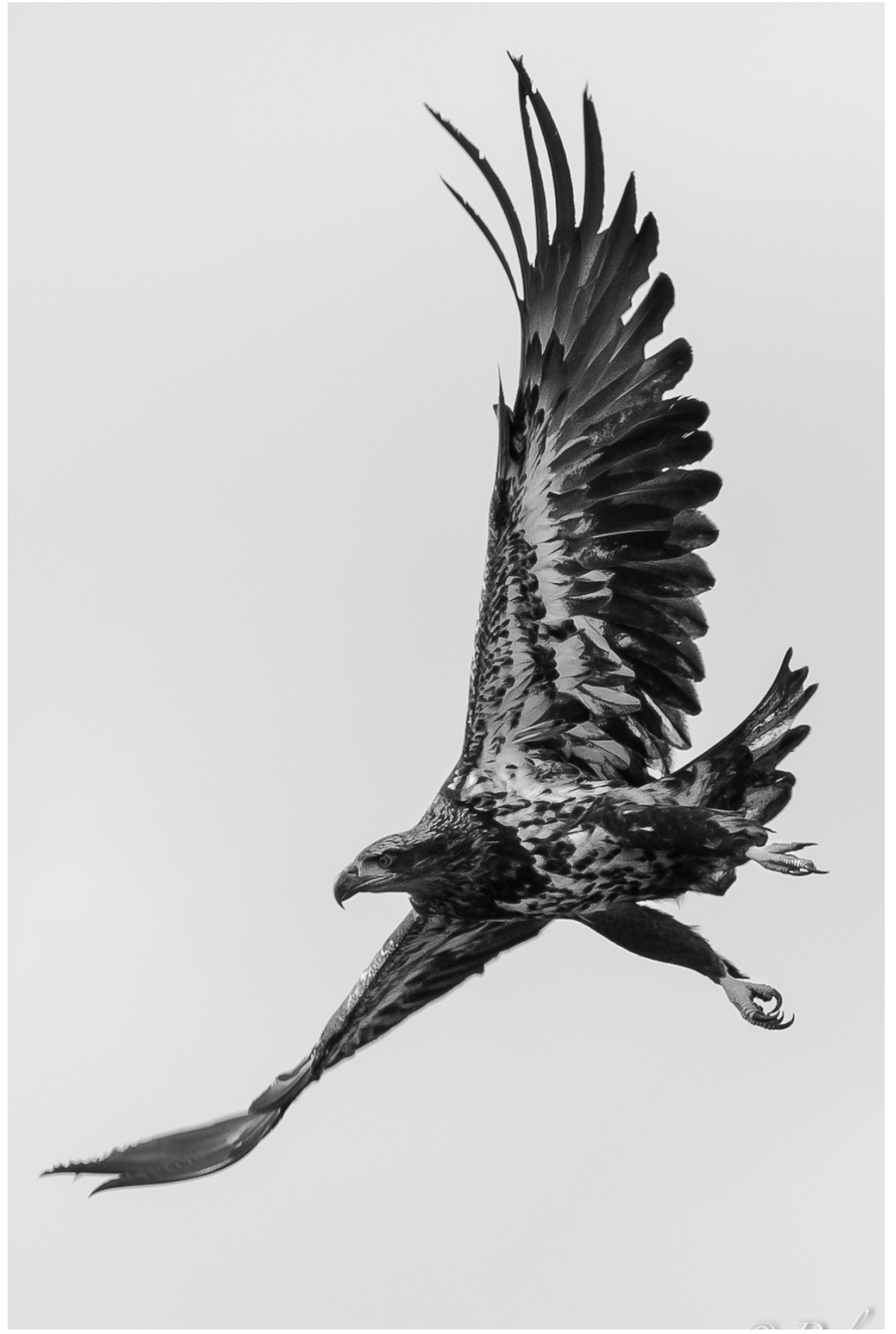

Figure 10 - Subadult bald eagle at McCulloch Island, 2013 